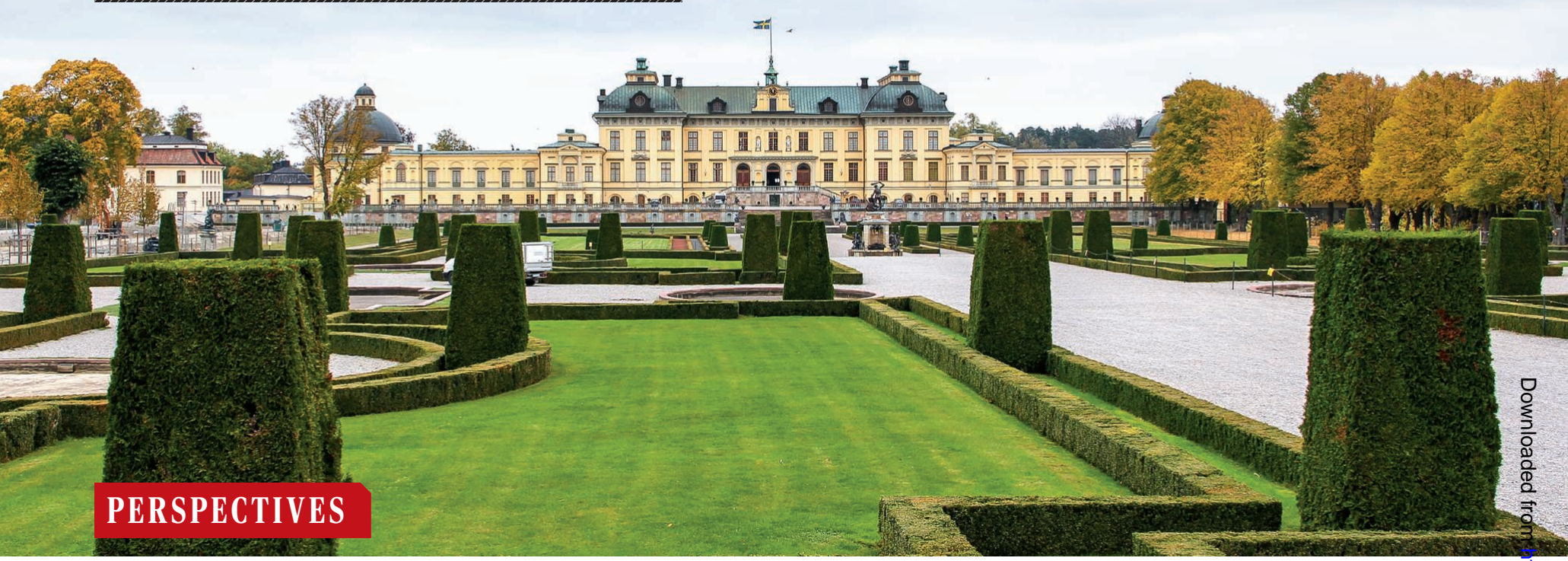

\title{
An alternative urban green carpet
}

How can we move to sustainable lawns in a time of climate change?

\section{By Maria Ignatieva ${ }^{\mathbf{1}, 2}$ \\ and Marcus Hedblom ${ }^{3,4}$}

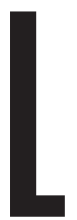

awns are a global phenomenon. They green the urban environment and provide amenable public and private open spaces. In Sweden, $52 \%$ of the urban green areas are lawns (1). In the United States, lawns cover $1.9 \%$ of the country's terrestrial area (2) and lawn grass is the largest irrigated nonfood crop (3). Assuming lawn would cover $23 \%$ of cities globally [on the basis of data from the United States and Sweden (1)], it would occupy 0.15 million to 0.80 million $\mathrm{km}^{2}$ (depending on urban definitions)-that is, an area bigger than England and Spain combined or about $1.4 \%$ of the global grassland area. Yet, lawns exact environmental and economic costs, and given the environmental and economic impacts of climate change, it is time to consider new al-

${ }^{1}$ School of Design, University of Western Australia, 35 Stirling Highway, Perth, WA 6001, Australia. ${ }^{2}$ Department of Urban and Rural Development, Swedish University of Agricultural Sciences, Post Office Box 7012, Uppsala SE-75007, Sweden. ${ }^{3}$ Department of Ecology, Swedish University of Agricultural Sciences, Post Office Box 7044, Uppsala SE-75007, Sweden. ${ }^{4}$ Department of Forest Resource Management Swedish University of Agricultural Sciences, Umeå SE-90183, Sweden. Email: maria.ignatieva@uwa.edu.au; marcus.hedblom@slu.se ternative "lawnscapes" in urban planning as beneficial and sustainable alternatives.

Although lawns are widespread, their properties have received less attention from the scientific community compared to urban trees or any other types of green areas. Designers, urban planners, and politicians tend to highlight the positive ecosystem services provided by lawns. For example, lawns produce oxygen, sequestrate carbon, remove air pollution (although this has not been supported by good quantitative studies), reduce water runoff, increase water infiltration, mitigate soil erosion, and increase groundwater recharging (4). But perhaps the most important positive ecosystem service is the aesthetic and recreational benefits they provide. Aesthetics are a primary factor in modern urban planning and landscaping practice. For example, in developing countries located in arid zones, designers argue that lawns and irrigated turfs considerably enhance the quality of urban life (5).

Recent heat waves and an increasing prevalence of droughts have raised economic and environmental concerns about the effects of urban lawns on climate change. These circumstances have encouraged researchers and the public to recon- sider the green-carpet concept and assess the controversial aspects of lawns. It has been argued that lawns moderate urban temperatures, but this when compared to the absence of any vegetation. In arid regions of the United States, lawn irrigation accounts for $75 \%$ of the total annual household water consumption (6). In Perth, Australia, the annual volume use of groundwater for irrigating public greenspaces is 73 gigaliters (Gl) and an additional 72 Gls of water in unlicensed backyard bores for private lawn irrigation (7). Another concern is the contamination of groundwater or runoff water due to overuse of fertilizers, herbicides, and pesticides. In 2012, the U.S. home and garden sector used 27 million $\mathrm{kg}$ of pesticides (8). The positive effect of soil carbon sequestration on the climate footprint of intensively managed lawns was found to be negated by greenhouse gas emissions from management operations such as mowing, irrigation, and fertilization $(9,10)$. Gasoline-powered lawn mowers emitted high amounts of carcinogenic exhaust pollutants (11). Moreover, substituting degraded open green areas with plastic lawns eliminates real nature from cities and arguably reduces overall sustainability given that they 
reduce habitats, decrease soil organisms, pollute runoff water, and may well have yet unknown negative consequences for human health through plastic particles.

However, the most noticeable constraint to new alternative lawn thinking may be the contribution of lawns to urban aesthetic uniformity (12) and urban ecological homogenization, where lawn plant communities become similar across different biophysical settings (13). From the vast variety of the grass genera, only a limited number of species are selected for lawns. In cold-season countries, Festuca rubra, Lolium perenne, Poa pratensis, and Agrostis spp. are the most frequently used grasses, and in warm-season countries, Cynodon dactylon, Paspalum spp., Stenotaphrum secundatum, and Zoysia japonica are the dominant species. In many regions, lawn grasses are becoming invasive. The main intent of lawn care is to keep the dominance of only a few species and eliminate the presence of others (all considered as lawn weeds).

The reason behind lawn uniformity may lie in its origin. Grass plots in ornamental gardens most likely appeared in medieval times and were probably obtained from the closest pastures and meadows. They were small and quite biodiverse (containing a large number of meadow herbaceous plants). In the 17 th century, the role of lawns increased in the decorative grounds of geometrical gardens. For example, in iconic French Versailles, short-cut green grass was perfectly blended with the ideology of the power of man over nature. The English landscape, or the "natural" style of the 18th century, introduced an idealized version of urban nature: grazed grasslands with scarcely planted shade trees and the "pleasure ground" next to the mansion with a short, smoothly cut lawn. With the introduction of mowers and lawn-seed nurseries, the English pastoral vision flourished further in the public parks during the second half of the 19th century. In the 20th century, the modernistic prefabricated landscape was based on the same English picturesque model as the "natural" landscape, which was often mistaken for ecological quality. Consequently, monoculture and intensively managed lawnscapes dislodged the majority of native zonal plant communities in urban environments. At the beginning of the 21st century, perfect green lawns became part of the uptake by non-Western countries of the ideal Western lifestyle and culture (12).

Since the end of the 19th century, there have been numerous attempts to create alternatives to homogeneous short-cut conventional lawns. For several decades, British researchers tried to promote the idea of an urban meadow (infrequently mown) as an alternative to high-maintenance lawns. There are different typologies of such urban meadows: (i) Sheffield's "naturalistic herbaceous plantings" (mixed native-exotic meadows of native grasses and different herbaceous plants with added planted exotic forms from the Himalayas and East Asia, Caucasus, or the United States); (ii) pictorial meadows generated from seed mixtures of native and exotic colorful annuals [the most visible example of this realization (i and ii) is the Queen Elizabeth Olympic Park in London]; and (iii) the use of mostly native meadow (prairie and tussock grasslands) plants in urban parks and private gardens, popularized in the United Kingdom, Northern Europe, United States, and New Zealand that was inspired from rich zonal vegetation (12). Unfortunately, none of these ideas flourished because the lawn has been an unquestioned norm and people perceive lawns as urban nature.

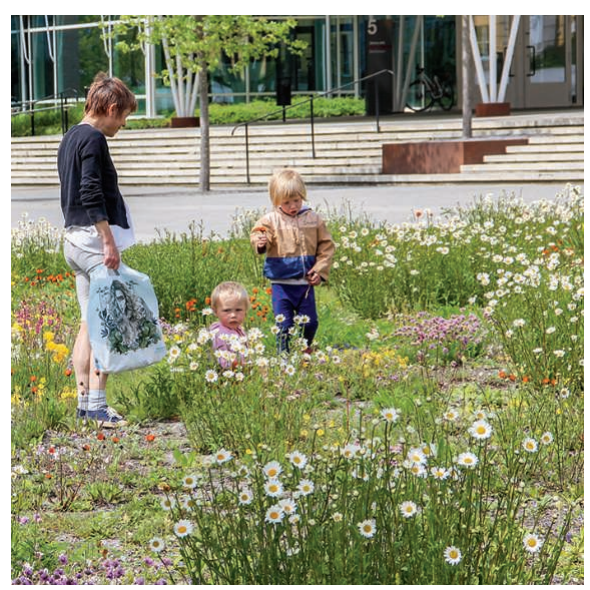

An alternative grass-free (tapestry) lawn boasts native plants in the Ultuna Campus of the Swedish University of Agricultural Sciences, Uppsala, Sweden.

What is the state of alternative lawnscapes today? The most dramatic implementation of new lawn thinking is in Berlin, Germany, where spontaneous vegetation is accepted as a fundamental landscape design tool. In Gleisdreieck Park and Südgelände Nature Park (both established on abandoned railways), some areas were left to "go wild" and thus have been colonized by spontaneous vegetation. This has successfully challenged societal norms of conventional green lawns and has been accepted by local people. Recent research in the United Kingdom and Sweden showed that people desire to change the monotonous lawn to a more diverse environment (12, 14). Grass-free lawn is one of the latest movements in both nations and is based on the use of low-growing native (in Sweden) or native and exotic (in the United Kingdom) herbaceous plants without the use of grasses. The goal is to create a dense biodiverse and low-maintenance mat, which can be used for recreation (15).
What about future research on urban lawns? Of course, new plant species that can survive heavy tramping or long drought, for example, are desirable. Beyond plant research, studies on planting design must go beyond the theoretical. Specific geographical, cultural, and social conditions of each country must be factored into such alternative lawn planning research. In Australia, South Africa, and Arizona, alternative lawns might be based on xeriscape local plants. In Chinese cities, historically proved groundcover species could provide sustainability and a sense of place. Lawns could become a universal model for experimental sustainable design and urban environment monitoring.

New alternative lawns represent a new human-made "wild" nature, which is opposed to the "obedient" nature of conventional lawns. Creating a new, ecological norm requires demonstration displays, public education, and the introduction of "compromised" design solutions. For example, a strip of conventional lawn can frame prairie or meadow and other "wild" vegetation and show a presence of culture in nature. The use of colors such as gray, silver, yellow, and even brown in lawnlike covers can add a feeling of real nature. Thus, one crucial challenge is how to accelerate people's understanding of sustainable alternatives and acceptance of a new vegetation aesthetic in urban planning and design.

\section{REFERENCES AND NOTES}

1. M. Hedblom, F. Lindberg, E. Vogel, J. Wissman, K. Ahrne, Urban Ecosyst. 20,1109 (2017).

2. G. L. Thompson, J. Kao-Kniffin, Crop Sci. 57, S238 (2017).

3. M. Simmons, M. Bertelsen, S. Windhager, H. Zafian, Ecol. Eng. 37, 1095 (2011)

4. J. A. Monteiro, Urban For. Urban Green. 26, 151 (2017).

5. E. M. Elgizawy, Procedia Environ. Sci. 34,131 (2016).

6. C. Milesiet al.,Environ. Manage. 36, 426 (2005).

7. D.Lieb, D. Brennan, D. McFarlane, "The economic value of groundwater used to irrigate lawns and gardens in the Perth metropolitan area" (Commonwealth Scientific and Industrial Research Organisation, National Research Flagships, 2007).

8. Environmental Protection Agency (EPA),"Pesticides industry sales and usage,2008-2012 market estimates" (EPA, 2017); www.epa.gov/sites/production/files/2017-01/ documents/pesticides-industry-sales-usage-2016_0.pdf.

9. C. Gu, J. Crane II, G. Hornberger, A. Carrico, J. Environ. Manage. 151, 233 (2015)

10. P.Tidåker, T. Wesström, T. Kätterer, Urban For. Urban Green $21,80(2017)$

11. J. Banks, "National lawn and garden equipment emissions," 2015 International Emission Inventory Conference, San Diego, CA, 16 April 2015; https://www3.epa.gov/ttn/chief/ conference/ei21/session10/banks_pres.pdf.

12. M. Ignatieva, in Urban Biodiversity: From Research to Practice, A. Ossola, J. Niemelä, Eds. (Routledge, 2018), pp. 216-235.

13. C. Polsky etal., Proc. Natl. Acad. Sci. U.S.A. 111,4432 (2014).

14. G. E. Southon, A. Jorgensen, N. Dunnett, H. Hoyle, K. L. Evans, Landsc. Urban Plan. 158, 105 (2017).

15. L.S. Smith, M. D. E. Fellowes, Urban For. Urban Green. 13, $433(2014)$

\section{ACKNOWLEDGMENTS}

We thank Formas, the Swedish Research Council for Environment, Agricultural Sciences and Spatial Planning (225-2012-1369, Lawn as ecological and cultural phenomenonSearch for sustainable lawns in Sweden) for financial support.

10.1126/science.aau6974 


\section{Science}

\section{An alternative urban green carpet}

Maria Ignatieva and Marcus Hedblom

Science 362 (6411), 148-149.

DOI: $10.1126 /$ science.aau6974

ARTICLE TOOLS

RELATED

CONTENT

REFERENCES

PERMISSIONS http://science.sciencemag.org/content/362/6411/148

file:/content

This article cites 11 articles, 1 of which you can access for free http://science.sciencemag.org/content/362/6411/148\#BIBL

http://www.sciencemag.org/help/reprints-and-permissions

Science (print ISSN 0036-8075; online ISSN 1095-9203) is published by the American Association for the Advancement of Science, 1200 New York Avenue NW, Washington, DC 20005. 2017 @ The Authors, some rights reserved; exclusive licensee American Association for the Advancement of Science. No claim to original U.S. Government Works. The title Science is a registered trademark of AAAS. 